\title{
RISK MANAGEMENT FOR REDUCING TRANSPORTATION COST IN VIETNAM MARKET IN GLOBALIZATION ERA
}

\author{
LE THI VIET NGA ${ }^{1}$, DINH TRAN NGOC HUY ${ }^{2}$, VU ANH TUAN ${ }^{3} \&$ PHAM MINH DAT $^{4}$ \\ ${ }^{1,3,4}$ Thuongmai University Hanoi Vietnam \\ ${ }^{2}$ Banking University HCMC, Ho Chi Minh City Vietnam - International University of Japan, Japan
}

\begin{abstract}
Risk management is a vital element of a transportation enterprise, helping it to use its advantages on the path to success. Risk management is a scientific, comprehensive and systematic process of approaching risk to identify, control, prevent and minimize losses and losses, the adverse effects of risks in the process of implementing the works related to international transport services such as, warehousing, shipping, purchasing, insurance, customs clearance, consulting services, ... for commercial goods in international trade. Transport greatly affects the cost of circulation, distribution and production and business of countries around the world.

Therefore, in this paper, by using qualitative, synthesis and statistics analysis, we analyze and evaluate the risk management aspects of transportation in reducing business cost in Vietnam and consequences for the economy became a lesson for Vietnam as well as developing countries. Proper solutions and development orientation as well as risk management (RM) for transportation in supply chain are given toward sustainable development for the economic system, thereby contributing to social security, thus contributing to the society welfare.

KEYWORDS: Transportation, Logistic, Risk Management, Cost Reduction. Commerce, Supply Chain, Society Welfare, Policies, Sustainable Development

JEL: F10, F18, M16
\end{abstract}

Received: Jun 08, 2020; Accepted: Jun 28, 2020; Published: Aug 28, 2020; Paper Id.: IJMPERDJUN2020922

\section{INTRODUCTION}

Transportation is a special material industry, always accompanying the evolution of human civilization, in order to exchange the position of goods and people themselves from one place to another safely.

Transportation is an integrated, diversified technical - economic industry, linked to the national infrastructure, solving production, business and distribution problems for each country and the globe by modern technology, transparent delivery laws enforced by a skilled team. This is a special material industry, always accompanying the evolution of human civilization, creating new products such as port containerization and logistics. 


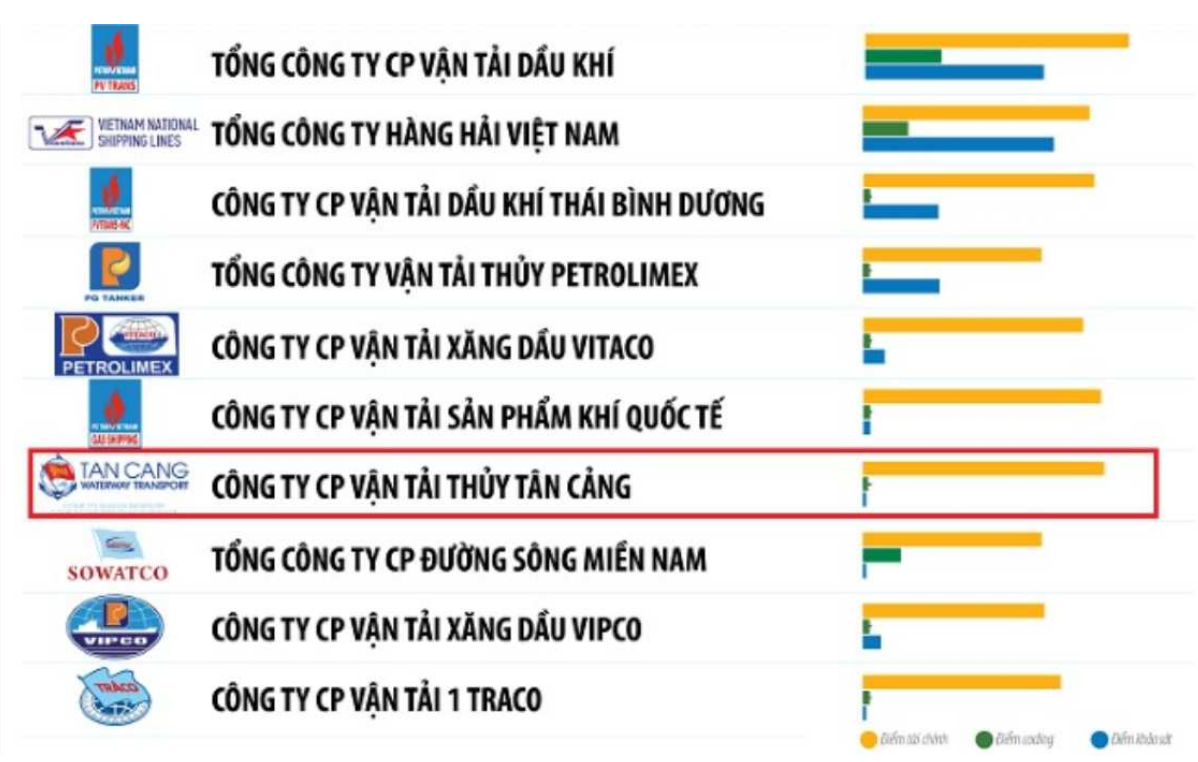

Figure 1: Top 10 Companies in Cargo Transportation and Logistic 2019.

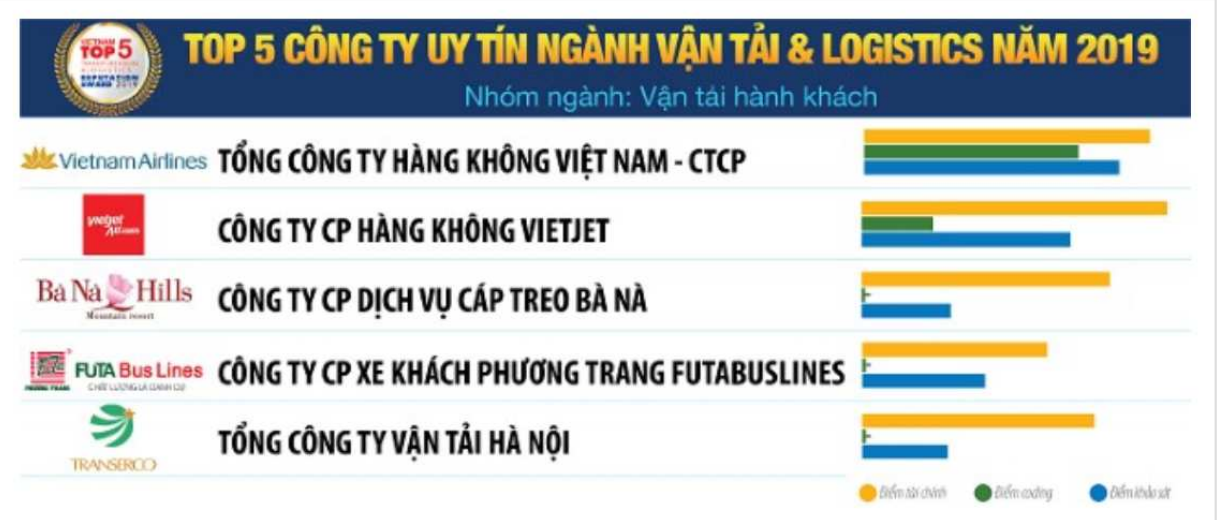

Figure 2: 2019 List O Top 5 Companies in Passenger Transportation and Logistic.

Once risk mangers realize that reducing cost will enable to lower insurance premium, then they can begin to implement RM programs to reduce insurance premium and then reduce costs.

The paper is organized as follows: after the introduction, it is the research issues, reviewing and comparing previous studies. Next, part 3 will include methodology and data and part 4 will present the main research results. Section 5 provides us with some policy discussion, conclusions and recommendations that will be covered in section 6 while section 7 covers solutions for risk management.

\section{RESEARCH CONTENTS}

Research Issues

The scope of this study will include:

- Research issue 1: What are positive and negative aspects of transportation in emerging markets such as Vietnam market.

- Research issue 2: Risks and mitigation measures, risk management in transportation. 


\section{Previous Studies}

Dias et al. (2005) proposed Supply chain risk management (SCRM) has a strong influence on the cooperation among partners and the performance of the entire production chain. A supply chain designed to minimize risks enables firms to establish a competitive position and provides long-term benefits to stakeholders. The SCRM system should be structured to manage both routine and extraordinary risks, such as natural disasters and major accidents. The risks should be managed both reactively, by monitoring changes in the chain, the needs of customers, technology and the strategies of suppliers and competitors, among others, to enable quick reaction to events; and proactively, to identify risks and implement actions to prevent them or minimize their impacts.

SCRM studies show several distinctive research approaches to investigating risk mitigating strategies. According to Ritchie and Brindley (2007), the decisions on the measures can be differentiated by the operational, tactical and strategic levels. From this perspective, the first approach in Figure 1 is completely limited to operational and tactical measures that are effective to mitigating individual risks (see Chopra and Sodhi, 2004; Pujawan and Geraldin, 2009). This focuses on identification and measurement of individual risks, thereby generating direct solutions rather than overarching corporate strategies. Although the second approach starts from analysis of risks similar to the first approach, its holistic risk analysis to find out the risk sources, loss types and root causes may lead the risk mitigation to the strategic level (see Ellegaard, 2008) as well as the operational/tactical levels. Compared to the previous approaches, the third approach focuses solely on the strategic measures by applying theories and research frameworks in the SCM or other management disciplines (see Bode et al., 2011; Christopher et al., 2011).

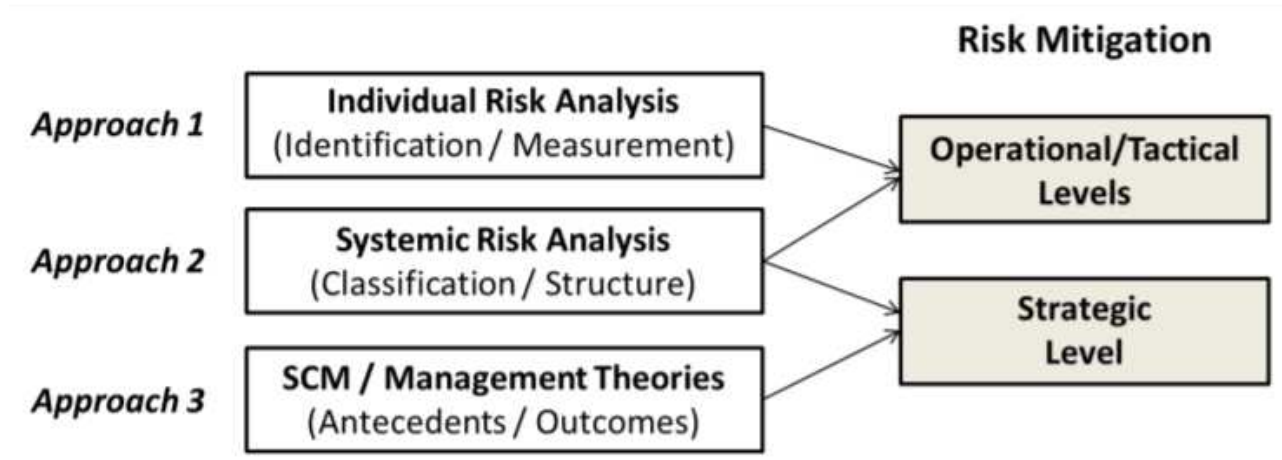

Figure 3: Three Research Approaches to Risk Mitigation (Source: Orca.cf.ac.uk).

Beside, Wee et al. (2012) stated Risk Management has become the key in avoiding business losses. Logistics interruption can come from an unforeseen exogenous event such as an earthquake or from an endogenous event, like the Toyota Quality recalls in 2010 that interrupted enterprise logistic operations and degraded its performance

Ceryno et al. (2013) mentioned there is at least partial evidence that risk management into supply chain can mitigate the negative effect of risk by different risk management strategies.

So far, many studies have been done in this transportation and logistic area, however, this article provides specific recommendations for emerging markets such as Vietnam based on an analysis of lessons learned by other countries around the world including India, China, Japan, etc. 


\section{METHODOLOGY}

This research paper uses qualitative research and analysis methods, logical analysis, deduction and synthesis to provide direction and solutions, dialectical materialist methods combined with historical materialistic methods. Consider assessing phenomena, things, economic objects, inductive interpretation methods and evidences in the economy to contribute to economic reality.

In addition, this paper uses general data analysis methods and draws lessons from other countries to comment on the results, then propose policies based on these analyzes.

\section{MAIN FINDINGS}

Overview of Vietnam transportation and logistic

Logistics is always associated with the transportation of goods production and circulation. Production raw materials are transported from raw material areas to production places by car, train, ship, Consumer goods at markets and supermarkets are transported by sea or road. All processes in the logistics chain are connected by transport.

In Vietnam, sea transport is much developing, the main form of transporting goods in large quantities. In which, the North-South shipping route with 2 major ports in Ho Chi Minh City and Hai Phong is being exploited strongly.

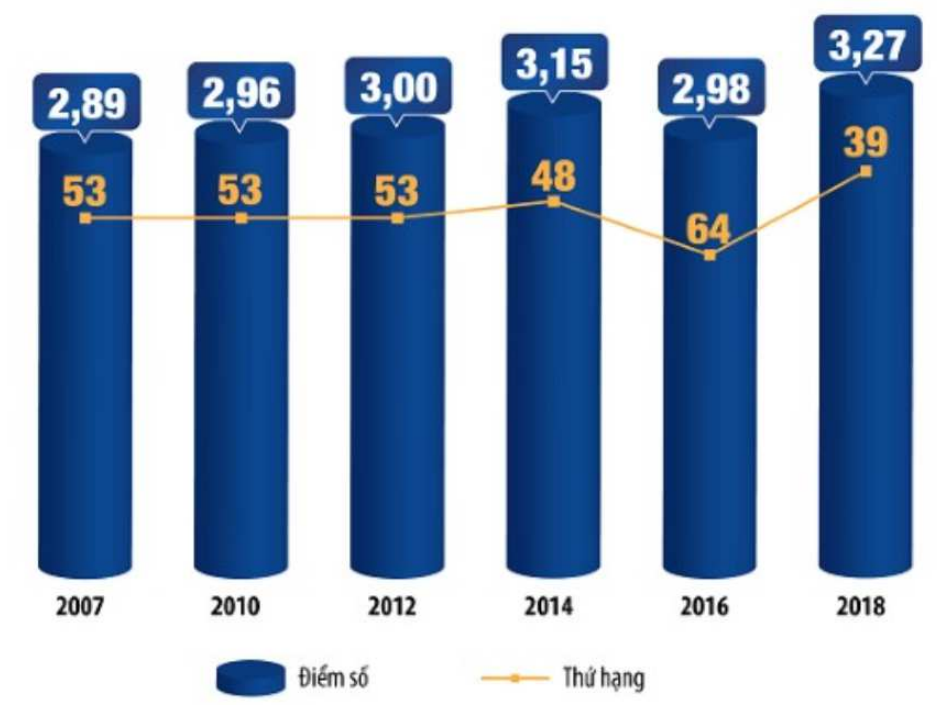

Figure 3: Logistics Performance Index (LPI) Vietnam from 2007 to 2018 (Source: Survey Report on Logistics Performance Index (LPI) 2018 of the World Bank).

\section{SWOT Analysis on Vietnam Transportation}

\section{Opportunities}

Transport greatly affects the cost of circulation, distribution and production and business of countries around the world. Recently, the revolution "electronics - digitization" and "information - communication" has promoted the rapid development of transport in science - technology, in order to create efficiency and competition in the marketplace. In less than a century, global seaports containerization and logistics have appeared. This will be a favorable premise for carriers as well as logistics operations to plan their transportation strategies in line with reality, bringing high efficiency. 
Form the below chart, we can see transportation turnover in Hanoi and HCM city till 2017:

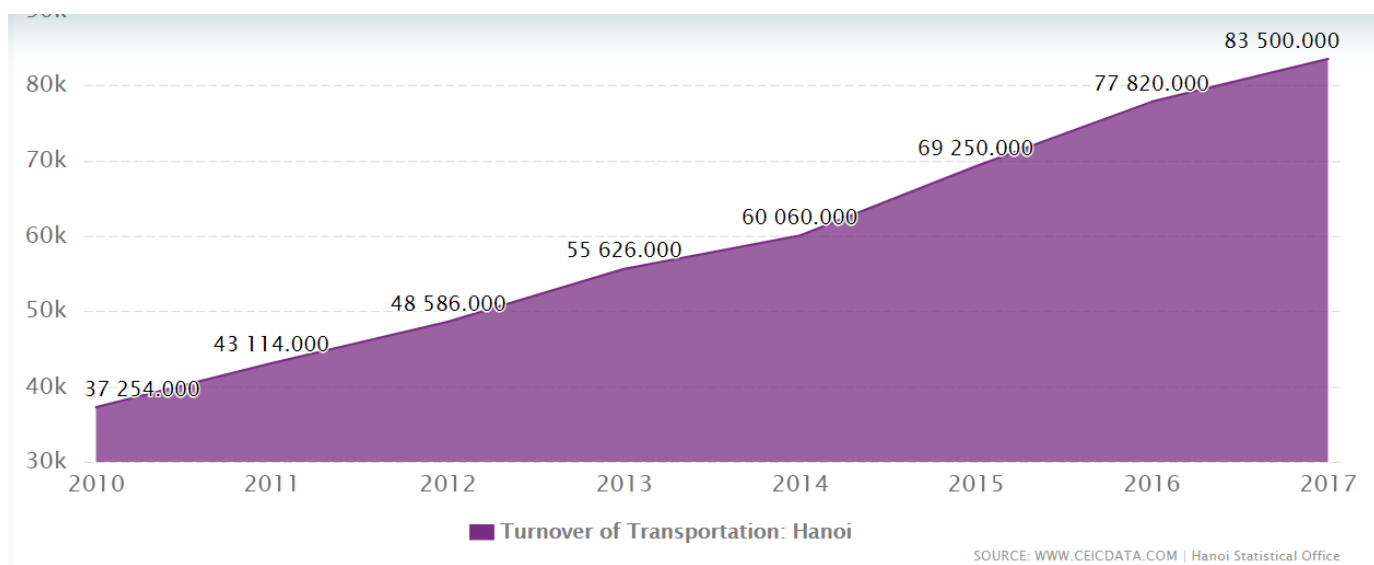

Chart 1: Hanoi Reached an All-Time High of 83,500.000 VND bn in 2017.

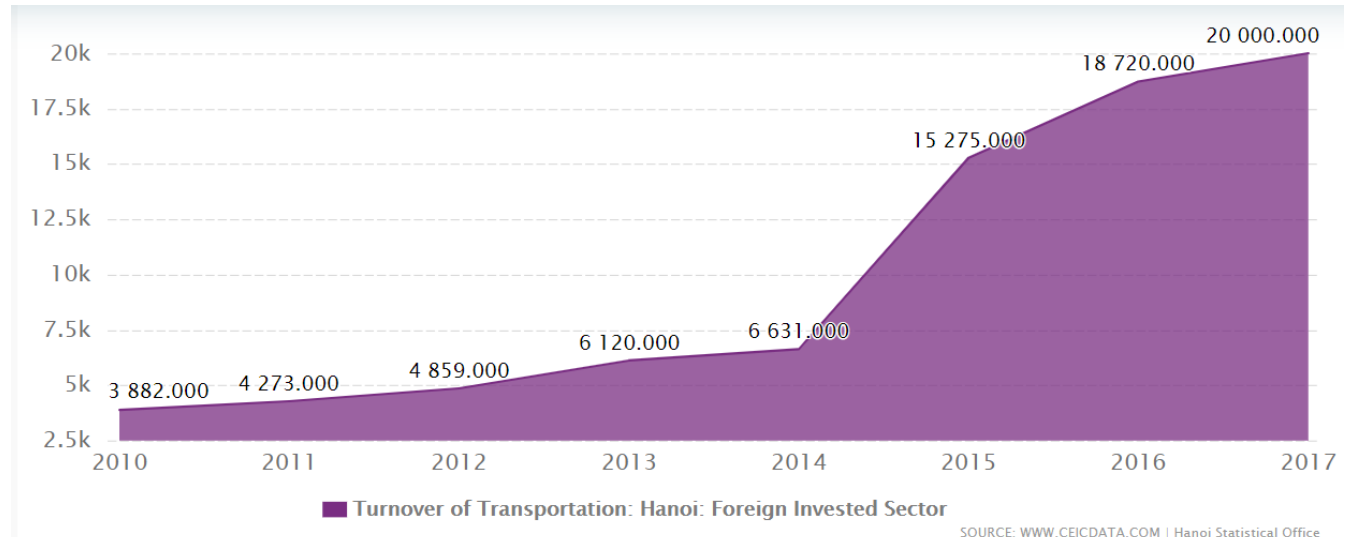

Chart 2: Foreign Invested Sector Reached 20 bn VND.

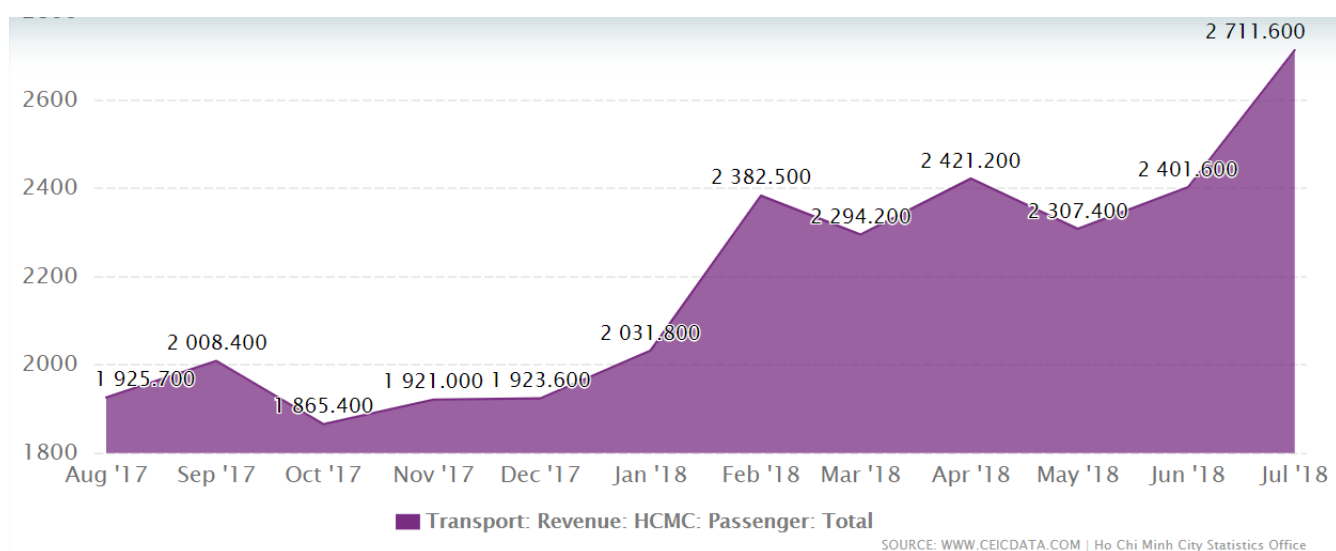

Chart 3: HCMC Reached an All-Time High of 2,727.600 VND bn in Feb 2016.

\section{Threats}

Risk happening if drivers not trained properly

Goods arrive later than the time specified in the contract

Damage to goods during transportation is less common, but nothing can guarantee $100 \%$, especially for some fragile items such as glass, and ceramic. 


\section{Strengths}

Car transport: thorough, able to transport from door to door. Car transportation helps collect and deliver goods at locations far from ports, stations or loading points. Road transport is flexible in the transport process, regardless of the time.

The biggest advantage of air transport is its high speed. The aircraft has the highest speed of all transport modes today. Average freight or passenger aircraft have an average speed of about $800-1000 \mathrm{~km} / \mathrm{h}$.

Rail transport also plays an important role in the flow of goods. Rail can transport large quantities of goods, with a stable speed and lower cost than road.

Air transport: Due to the outstanding advantages of air transportation for high value shipments, prompt shipping is required to ensure quality. The advantages of air transport have contributed to reducing risks in the circulation of shipments, thereby improving the overall quality of logistics services and reducing the cost of goods losses in the supply chain. .

Shipping: This type of transportation is most used in the modes of transporting goods because it has many advantages: sea transport has a large carrying capacity thanks to large vessels, especially. new generation container ships; low transportation costs due to large ship tonnage. Sea freight is suitable for transporting goods in international trade.

\section{Weaknesses}

- Need to establish sound legal framework and regulation for transportation;

- Poor quality shipping service is shown as: employees are not respectful or enthusiastic about customers, goods are delivered late, contact with customers is poor, goods are lost or damaged. broken, ...

- Big cost: The cost of shipping via air is much larger than the cost of shipping by other form. Therefore, it is only suitable for luxury items or requires fast shipping. There are a lot of regulations related to regulations and laws when flying by air to ensure flight security and safety. External effects: Due to bad weather, storms ... the flight may be delayed

\section{Risk Analysis of Transportation}

For instance, in sea shipping, there are several risks such as:

- Missing + wrong papers: This is the case we most often encounter. Most businesses will be very difficult to handle if businesses are not familiar and do not know how to get these documents back. Forwarder companies like we meet a lot, so we always have a link to support processing these documents, from authorization papers.

- Failure of goods: box distortion is not uncommon for sea transport. If you don't find a really good trucking company, the goods even break down on a regular basis.

- Risk of natural disasters: The sea is particularly affected by natural disasters and depends on the weather, so when choosing sea transportation you will have to accept it risk of shipping goods with time. Transit times are longer or difficult to meet urgently needed. These are the permanent losses to sea transport that shippers always have to pay attention to and have an array of prevention for these segments. 
- In addition, there are a number of other risks such as shipwrecks, shipwrecks, loss of cargo are risky cases that other modes of transport are often required, so we do not talk much in the article about transport risks. this sea way. Talk about possible hazards in sea shipping.

- Human Risk: People also cause risks to goods when transporting at sea such as theft, theft, shortage or failure to deliver goods due to the illegal act of the master and crew.

\section{Regulation of Transportation in Some Countries}

In Japan, in April 2017, crypto currencies are under Payment Service Act, in which it regulated Money Laundering as follows: "The cryptocurrency exchange businesses are obligated to check the identities of customers who open accounts, keep transaction records, and notify authorities when a suspicious transaction is identified". Market will adjust itself and some crypto currencies

\section{Experience and Lessons from Transportation in Other Countries}

In many countries for sea shipping risks, there are many ways to limit and handle these risks in sea transport but there are two most effective ways:

Experienced in preparing the risks; and for risks that cannot be prevented, you should buy insurance, then when there is a risk, insurance will cover it, although this is not a small amount for goods. The value per shipment is very large, so instead of buying insurance money, buying it will help you a lot if there is a risk.

In India, they construct production facilities for battery-powered electric vehicles.

In China, they promotes the use of E10 (10\% bioethanol) as an alternative transportation fuel option. China also promotes vehicles using gas, mainly CNG, and vehicles using LPG.

In Japan, to reduce loss further, monitoring systems to control these consequences are attracting more interest. The current development of a structural monitoring system is introduced to demonstrate the advantage of monitoring-based management. The below figure shows risk management in Japan (note: BCM: Business Continuity Management)

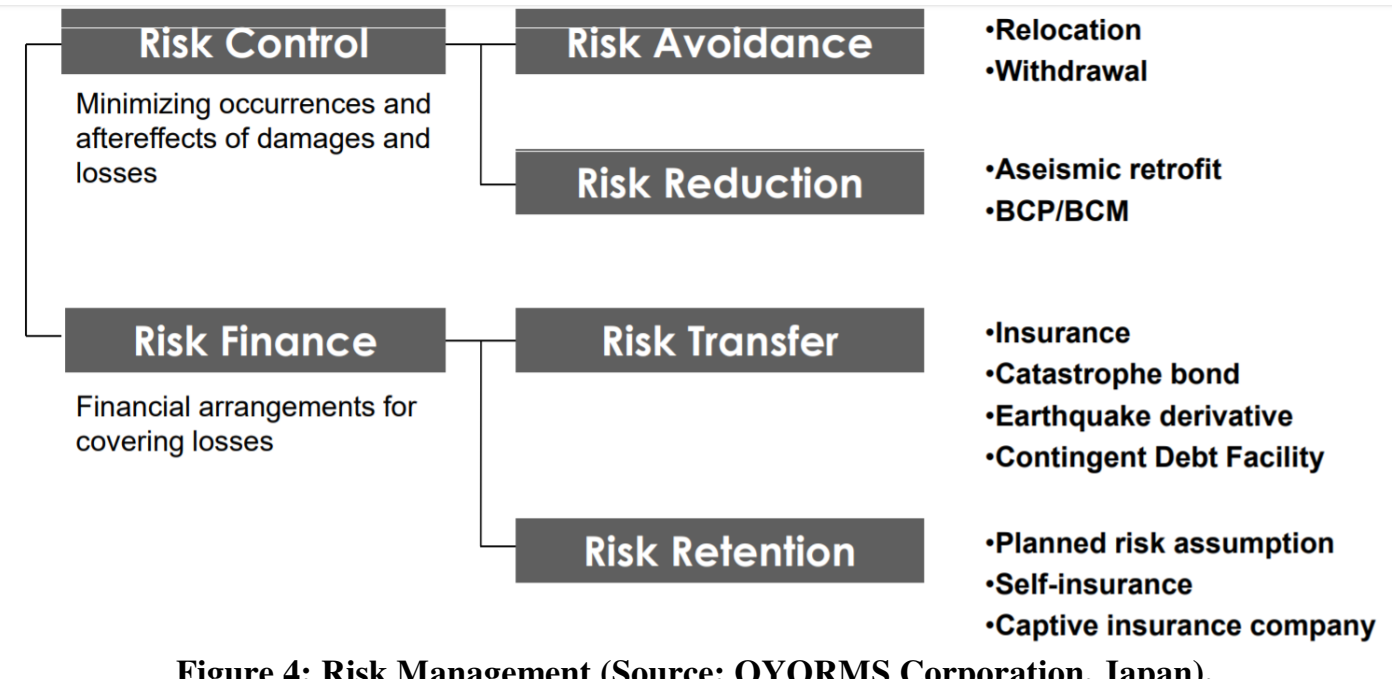

Figure 4: Risk Management (Source: OYORMS Corporation, Japan). 


\section{CONCLUSION AND POLICY RECOMMENDATIONS}

In this section, we will summarize risk management issues and propose risk management solutions to prevent and handle risks in transportation.

Depending on geographical features of each nation and region, risk levels might be vary.

Potential risks in transportation might be higher (in railway, car, airlines, sea...) if we do not implement such risk management solutions.

\section{Some Management Issues to Develop Effective Transportation Service}

- Price of transportation services are slow to adjust, even in case price of gasoline reduced;

- Currently, Vietnam's logistics service providers apply technology to their business activities at a low level, mainly using electronic customs declaration software, vehicle navigation technology, email and basic internet ..., but according to the judgment of nearly $80 \%$ of experts in the survey of Vietnam Report, before the digital trend, businesses in the Transport and Logistics industry in Vietnam will gradually adapt and promote their research. Research and apply technology in logistics activities to standardize operating processes, optimize costs and resources of businesses

- Vietnam is recorded as one of the top 10 countries with the largest number of traffic accidents in the world and in big cities such as Hanoi and HCMC there are lots of traffic jams.

\section{PROPOSAL ON TRANSPORTATION RISK MANAGEMENT AND OPERATIONAL RISK}

Business risk includes everything (both internal or external) that affects brand, reputation, competitiveness, financial value or end status (i.e. efficiency, efficiency and its general success).

In most cases, we buy insurance for shipping and transportation. Insurance for risks encountered in sea transport is divided into two main categories:

- Insured risk: when natural or unintended such as storm, tornado, shipwreck, missing, stranded, collision or fire, the user of cargo insurance will be provided by the service provider. absolute compensation.

- Risks are separately insured: destructive activities from human (war, civil war, strike, theft, piracy) to be covered need a number of separate terms and agreements between the two sides. If the insurance user does not buy insurance for a particular type of risk, as specified in the contract of carriage, then these risks are considered to be in the exception group.

- Exception: are risks resulting from intentional actions of people or goods of natural nature that are not covered.

- Use air shipping: as Safety assurance: transport by plane also has the highest safety. The risk of using an airplane is much less than that of road, rail, and sea. So the goods will always be guaranteed, not be lost or damaged or lost. Minimize losses incurred by handling, breakdown, or petty theft.

Beside, We Recommend the Risk Management Model for Businesses as Follows

Enterprises can use 1 of 3 models (or mix with modified models) as follows: 
- Model 1: Set up a department in charge of financial risk management. This model is suitable for large-scale enterprises, such as economic groups. Enterprises can choose 1 of 2 modes:

- Establish a risk management department, a financial risk management department under the risk management department.

- Set up a department in charge of financial risk management under the financial management department.

- Model 2: Part-time parts of financial risk management. This is a model for midsize businesses. The enterprise does not set up a department in charge of financial risk management, but simultaneously implements a financial risk management system by selecting personnel from the existing financial management department, training in financial risk. financial risk management and management, in conjunction with consulting organizations and experts in the field of financial risk management to use financial risk management forms and programs. The assigned administrators will then be responsible for implementing the solutions of the designed financial risk management program, with the support of the organization and agreed consultants. Therefore, the company combines the activities of part-time financial risk managers with the advice and support of experts in the development and implementation of financial risk management programs.

Expected effects of lower costs associated with less risky industries. The riskier the industry, the higher management cost and vice versa. Hence, we need to reduce risk in transportation industry as much as possible.

\section{ACKNOWLEDGEMENTS}

I would like to take this opportunity to express my warm thanks to Board of Editors, Professors, my family, my colleagues in assisting convenient conditions for my research paper.

\section{REFERENCES}

1. Allen, H. (2003). Innovations in retail payments: e-payments. Bank of England Quarterly Bulletin, 43(4), 428-438.

2. Ceryno, P.S., Scavarda, L.F., Klingebiel, K., \& Yuzgulec, G. (2013). Supply Chain Risk Management: A Content Analysis Approach,International Journal of Industrial Engineering and Management (IJIEM), 4(3): 141-150

3. Sodhi, M. S., Son, B., \& Tang, C. (2012). Researchers' perspectives on supply chain risk management. Production and Operations Management, 21(1), 1-13. http://dx.doi.org/10.1111/j.1937-5956.2011.01251.x. [ Links ]

4. Swait, J., \& Adamowicz, W. (2001). The influence of task complexity on consumer choice: a latent class model of decision strategy switching. The Journal of Consumer Research, 28(1), 135-148. http://dx.doi.org/10.1086/321952.

5. Dias, G.C., Hernandez, C.T., \& Oliveira, O.R. (2020). Supply chain risk management and risk ranking in the automotive industry, Gest. Prod. vol.27 no.1 São Carlos 2020 Epub Jan 20, 2020. https://doi.org/10.1590/0104-530x3800-20

6. Tainton, J., \& Nakano, M. (2014). The behavioural effects of extreme events in global supply chains. In B. Grabot, B. Vallespir, S. Gomes, A. Bouras \& D. Kiritsis (Eds.), Advances in production management systems, Part II. IFIP AICT (Vol. 439, pp. 62-70). Heidelberg: Springer. http://dx.doi.org/10.1007/978-3-662-44736-9_8.

7. Tang, C. S. (2006). Perspectives in supply chain risk management. International Journal of Production Economics, 103(2), 451-488. http://dx.doi.org/10.1016/j.ijpe.2005.12.006.

8. Wee H.M., Blos M.F., Yang WH. (2012) Risk Management in Logistics. In: Lu J., Jain L.C., Zhang G. (eds) Handbook on Decision Making. Intelligent Systems Reference Library, vol 33. Springer, Berlin, Heidelberg. 
9. Zeng, B., \& Yen, B. P. C. (2017). Rethinking the role of partnerships in global supply chains: A risk-based perspective. International Journal of Production Economics, 185, 52-62. http://dx.doi.org/10.1016/j.ijpe.2016.12.004.

10. Zhao, L., Huo, B., Sun, L., \& Zhao, X. (2013). The impact of supply chain risk on supply chain integration and company performance: a global investigation. Supply Chain Management, 18(2), 115131. http://dx.doi.org/10.1108/13598541311318773.

11. https://doi.org/10.1007/978-3-642-25755-1_15. https://www.sbv.gov.vn

12. https://nif.mof.gov.vn

\section{EXHIBIT}

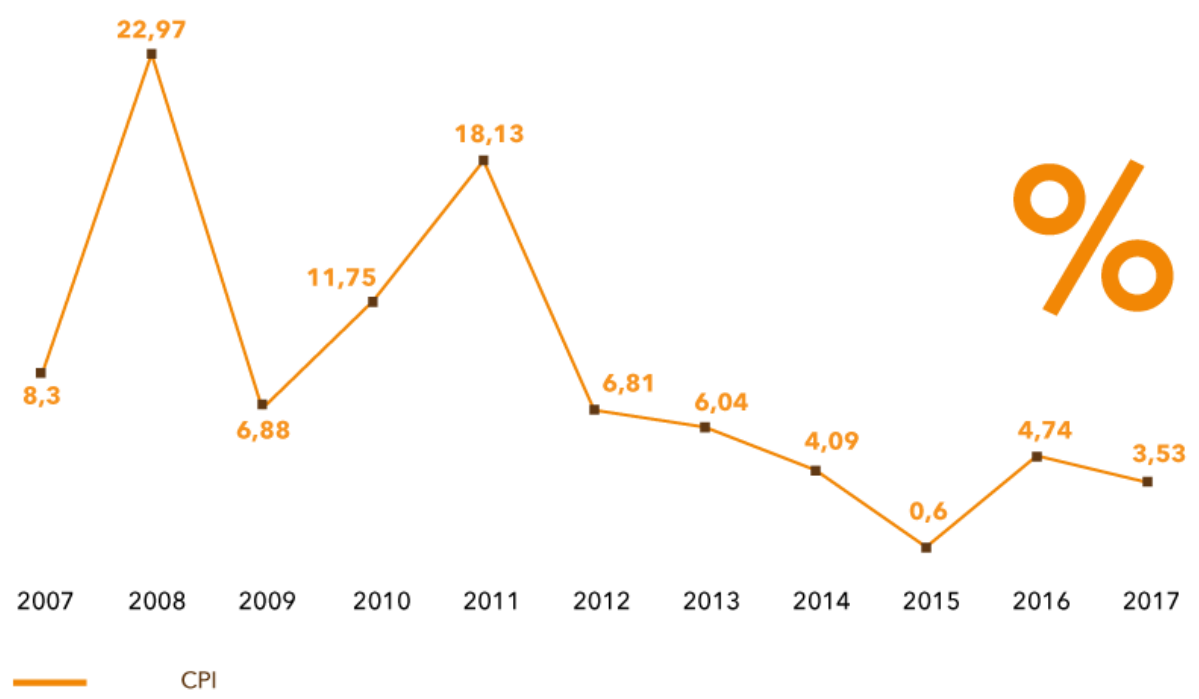

Exhibit 1: Inflation, CPI Over Past 10 Years (2007-2017) in Vietnam.

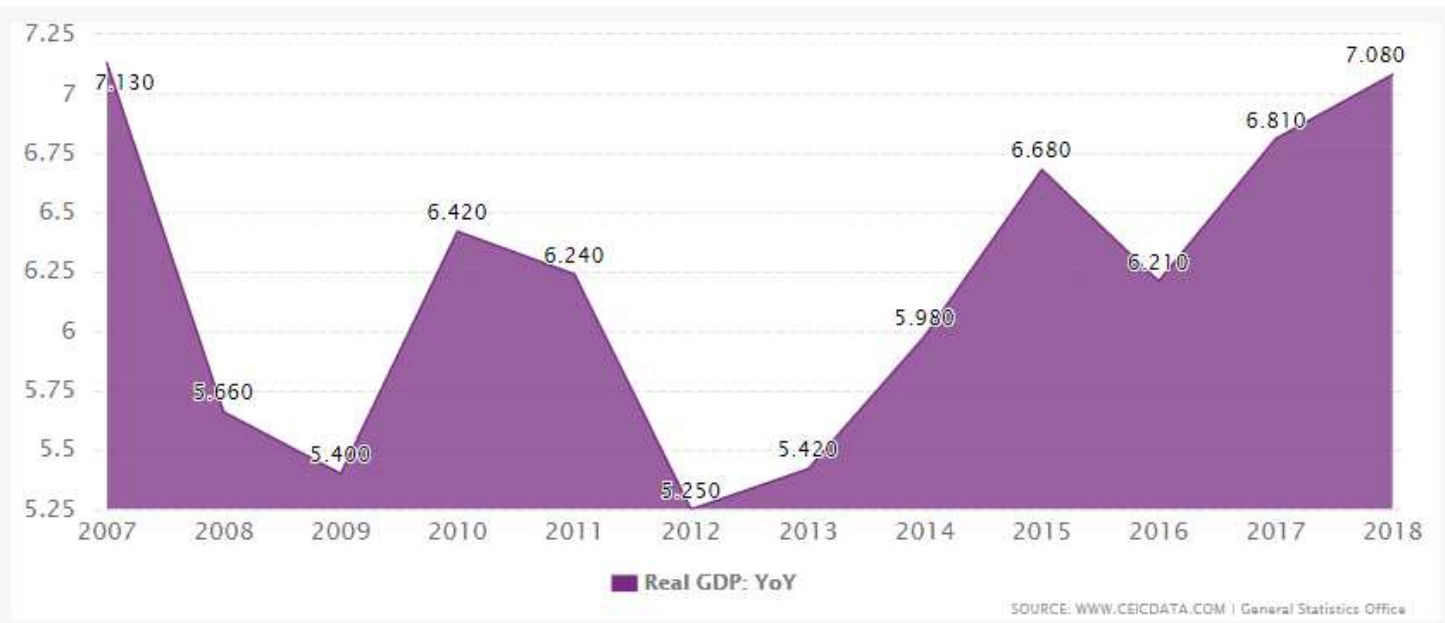

Exhibit 2: GDP Growth Rate Past 10 Years (2007-2018) in Vietnam. 